\title{
Using a Case Study Interactively to teach Sustainability Risk Management
}

\author{
Richard Roe $^{1}$, Walter Bardenwerper ${ }^{2}$ and Victoria Borkovskaya $^{3 *}$ \\ ${ }^{1}$ Georgetown University Law Center, Washington, DC, USA \\ ${ }^{2}$ Peking University School of Transnational Law, Shenzhen, China \\ ${ }^{3}$ Moscow State University of Civil Engineering, Yaroslavskoe shosse, 26, Moscow, 129337, Russia
}

\begin{abstract}
Enterprises whose operations may negatively affect the sustainability of the world around them face a variety of challenges by individuals, communities and governmental bodies who increasingly view the impact of these enterprises as detriments to the sustainability of our planet's resources. We examine the advantages of the interactive teaching of a case study in schools, universities, and trainings for enterprises and NGOs to explore how policies can be developed so that these enterprises can be economically and socially successful and at the same time operate consistently with sustainability.
\end{abstract}

\section{Introduction}

Managers of construction businesses and projects, like their counterparts across many segments of the global economy, have increasingly become aware of the multifaceted ways in which their operations may negatively affect the sustainability of natural resources and the living environment of the planet. Like other enterprises in energy, pharmaceuticals, manufacturing or transportation, owners and managers in the construction industry derive some of their profits by not having to bear all of costs of the negative externalities - the long- term degradation of the environment - of their operations. It has become increasingly imperative globally that these enterprises not only manage for profit, but at the same time operate consistently with sustainability. (FN - "Clean Up Climate Change? It's Just Good for Business," Washington Post, October 12, 2018, at www.washingtonpost.com/business/economy/clean-up-climate-change-its-just-good-forbusiness/2018/10/12/30f13e40-cda2-11e8-920fdd52e1ae4570_story.html?utm_term=.65ac$59 \mathrm{a} 0 \mathrm{c} 406 /)$.

How do rising managers and workers in the construction industry learn about the sustainability-related externalities that arise from the operations of their enterprises and building projects? How can the construction industry provide its stakeholders with the tools to recognize, analyze and manage sustainability risk in their strategic planning and project execution? What are the advantages of interactive teaching using a case study in this or other fields.

In this article, we examine the interactive dimensions of a case study of the lawsuit, Village of Kivalina $\mathrm{v}$ Exxon Mobil, et al, originally designed for law and economics students, to explore these questions. While the case study approach is well known,

\footnotetext{
*Corresponding author: BorkovskayaVG@mgsu.ru
} 
particularly in law and business studies, this article focuses specifically on the interactive potential of case studies and the value of interactive teaching about sustainability.

The Alaskan village of Kivalina has suffered loss of land, prosperity and culture - and may face extinction as a community - due to rising temperatures and sea levels, Kivalina sued Exxon Mobil and a group of other large energy producers, claiming the energy industry knowingly releases greenhouse gases (GHG) into the air and has misinformed the public of the environmental harm which has now been catastrophically visited upon their native village. We will demonstrate how case studies such as this can be used, along with effective interactive teaching methodologies, to develop a multifaceted examination of sustainability risk issues in the construction industry, engineering and other enterprises.

Sustainability Risk. This article explores a number of problems: first, of educating the stakeholders in an industry about the economic question of who bears the cost of - and who may potentially be liable for - negative externalities that threaten sustainability and second, how should that question be posed and resolved in the wide variety of forums, both public and private, educational and corporate, and individual and collective, through education and advocacy. This paper suggests that since sustainability involves the integration of dynamic and interdependent forces and factors, teaching and learning about it should be approached through dynamic and interdependent learning methodology. We suggest that interactive learning, which brings multidimensional, integrative learning into the experience of the learners, is a preferred approach. In this paper, we describe how a case study of a legal case can be adapted to serve as a metaphor and an entry point to the complexity of the issue of sustainability.

At its most general level, sustainability refers to the capacity to continue an activity or process indefinitely. Sustainability involves any number of economic, social, or environmental activities, and the term can have varied meanings within different disciplines. The most frequently cited definition is that of the United Nations World Commission on Environment and Development 1987 (the 'Bruntland' Commission) in which sustainability is defined as "development that meets the needs of the present without compromising the ability of future generations to meet their own needs."

[FN World Commission on Environment and Development (1987). Our Common Future. Oxford: Oxford University Press]

In general, 'sustainability' and 'sustainable development' are used interchangeably. Sustainability risk management (SRM) is a business strategy that aligns profit goals with a company's environmental policies. The goal of SRM is to make this alignment efficient enough to sustain and grow a business while preserving the environment. Large enterprises with complex operations should be integrating SRM into their overall enterprise risk management processes and controls. This requires a broad understanding across the organization of how the enterprise interacts with the environment outside of the conventional limited scope of a particular project. The more complex the organization - the more raw materials it uses, the more disciplines it employs, the more suppliers it relies on, the more regulated its operations - the more likely it is to create a large environmental, and sustainability, footprint. The sustainability risks of a construction enterprise may relate to air quality degradation; soil and water contamination, toxic substances, occupational health and safety, noise pollution, local community relations, the health and well-being of employees, among other ecological and cultural issues. Impacts in each of these areas may be borne by others (externalities) or may directly impact a company's long-term financial results and its own sustainability, or both at the same time.

To function responsibly in the global economy, for the benefit of its own investors and management, but also for the preservation of a sustainable environment and infrastructure, a construction enterprise needs to perform effective socio-economic and environmental impact assessments and develop operational plans that correspond both to its own interests 
and promote a sustainable business environment. The same is true, for example, in the energy industry, where it has become increasingly evident to the general public that energy extraction and refinement operations impose costs on society which are not directly paid for by the enterprises themselves. As carbon-based emissions increase, a substantial body of climate scientists believe that the global climate is warming and ocean levels are rising.

Whatever the industry that generates negative externalities affecting sustainability, participants in that industry are increasingly called upon to manifest sensitivity to the sustainability risks their operations pose for society. How can sustainability risks best be taught and learned?

The Kivalina Case Study. One of the authors, Professor Bardenwerper, developed a case study from the energy industry derived from a major lawsuit that provided an underlying set of facts to "bring home" to law and economics students the issues of sustainability and negative externalities. The case was incorporated into an interactive classroom exercise which has been employed in the training of prospective lawyers and economists in both Russia and China.

The case study was based on a lawsuit filed by a municipality that contended it is suffering catastrophic damage due to rising sea levels caused by GHG emissions which have led to global climate change. This municipality was not the first, nor will it be the last, aggrieved party attempting to utilize litigation to extract damages from polluters allegedly contributing to these adverse environmental changes - in this case through the federal courts of the United States. [FN - FN/ See e.g., PRESS RELEASE "Baltimore Takes on Fossil Fuel Companies To Protect Taxpayers from the Costs and Consequences of Climate Change," Office of the Mayor, City of Baltimore, Maryland, July 20, 2018; "Three Californian Communities Sue 37 "Carbon Majors" Seeking Compensation for Costs of Adapting to Sea Level Rises Linked to Climate Change," Business and Human Rights Resource Centre, March 22, 2018 (Internet); Daniel A. Farber, "Basic Compensation For Victims of Climate Change," 155 U. Penn L. Rev. 1605 (2007)]

The Basic Facts: The Alaskan native village of Kivalina is a traditional Iñupiat Eskimo community of about 390 people about 625 miles northwest of Anchorage. It is built on an 8-mile barrier reef between the Kivalina River and the Chukchi Sea. Sea ice historically protected the village, whose economy is based in part on salmon fishing plus subsistence hunting of whale, seal, walrus, and caribou. But the ice is forming later and melting sooner because of higher temperatures, and that has left it unprotected from fall and winter storm waves and surges that pummel coastal communities. Villagers alleged in their lawsuit against Exxon Mobil and other large energy companies that their village is disappearing due to global warming and needs to move urgently before it is destroyed and the residents become global warming refugees. Kivalina's attorney, Matt Pawa of Boston, Massachusetts, has said Kivalina is "battered by winter storms, and if residents don't get some money to move, the village will cease to exist."

[FN "Kivalina, Alaska: Eroding Village Appeals Lawsuit's Dismissal, Blames Corporations For Climate Change". Huffington Post. 2010-01-28] and [FN - Montague, Ada C. (2013) "Native Village of Kivalina v. ExxonMobil Corp.," Public Land and Resources Law Review: Vol. 0 , Article 15. Available at: https://scholarship.law.umt.edu/plrlr/vol0/iss3/15.]

Ultimately, Kivalina was unsuccessful in its lawsuit, which was dismissed by the United States Court of Appeals on the grounds that U.S. federal law regarding clean air has been pre-empted by statute and that it is a matter for the political process to determine how, if at all, liability for global warming should be apportioned. The U.S. Supreme Court declined to review the ruling. Thus, the Alaskan villagers obtained no compensation and the global energy companies were spared what might have been almost incalculable liability costs. 
[FN Native Village of Kivalina v. ExxonMobil Corp., 696 F.3d 849, 2012 (9th Cir. 2012).

The Issues: Versions of this case study have been successfully taught in China and Russia. The manner of presenting the issues did not require a grounding in U.S. law; indeed, no legal training is required to effectively explore the issues raised by the case study.

These issues cross a range of sustainability implications for the energy industry and the public that are likely to have their analogues in the construction industry:

- How long have the energy companies known about the potential climate effects of carbon emissions?

- Could they have proactively developed technologies, or at least stimulated awareness among innovative minds, to mitigate the effect of the world's consumption of their product and the air pollution it has generated?

- Should there be a mechanism for imposing at last some of the externality costs back on the energy producers?

- Is the legal system an effective and appropriate mechanism for doing so?

- Would permitting lawsuits such as those filed by the Village of Kivalina to proceed to a verdict perhaps yield revelations about knowledge and responsibility through the discovery process that would be analogous to the disclosures that led to liability and compensation in the asbestos or tobacco cases?

- If private parties who are absorbing these external costs can't get redress through the legal system, and the political system is heavily influenced by energy producers' lobbyists, what are the possibilities for redress for communities like Kivalina?

\section{Materials and methods}

In general. As stated above, the practice of case studies is well known and there is considerable literature to guide teachers in the preparation and teaching of case studies. [FN - Michelle Schwartz, Instructional Design and Research Strategist, "Teaching Methods for Case Studies, the Learning \& Teaching Office, Ryerson College, 2014, available at http://ryerson.ca/lt. ] and [FN - Ann Velenchik, "Teaching with the Case Method, SERC Pedagogic Service Project, Carlton College. Available at https://serc.carleton.edu/econ/cases/index.html/].

Three Ingredients of a Lesson Plan: Objectives, Methods and Evaluation. The typical format for developing lesson plans for case studies includes three components: 1) objectives, 2) methods (including the case and the supporting materials), and 3) evaluation. However, the process of developing the lesson does not often proceed in such linear steps. While the teacher or training often has in mind as some learning outcomes, the teacher often uncovers a case or situation that strikes the teacher as an engaging scenario to develop the instructional concepts and themes sought. Then, deeper examination of the case itself aids the teacher to more fully develop the objectives. The articulation of objectives and methods is a dynamic process.

Objectives of the Kivalina Case Study. The objectives for teaching using a case study of Village of Kivalina v Exxon Mobil et al are to illustrate potential externalities that may be imposed by industrial undertakings beyond the range of ordinary business consequences customarily considered by managers and to get industry participants to think about their potential liability for the costs involved, and ways to potentially modify processes to reduce the severity of those costs while remaining economically viable. While, as noted above, this particular case study was created for law and economics students, it could easily be modified - or similar case studies designed — to serve the same purpose in the construction industry or other industries or fields, addressed to a range of prospective 
participants, including construction enterprise managers, engineers, workers, suppliers, subcontractors, as well as ordinary citizens and policy-makers.

Objectives are learning outcomes which can be observed in the operation of the class activities. Creating measurable objectives helps teachers devise assessment strategies to show how the learning can be evaluated or assessed. Here, the Kivalina case study is used as an introductory lesson to begin to introduce the learners to the concepts of sustainability and processes of risk management. In a full course on risk management, learners would move from this introductory stage to developing and applying knowledge and skills in the theory and practice of risk management. [FN - See Syllabus: "Enterprise Risk Management, Fourth Quarter 2017, Peking University School of Transnational Law," Professor Walter Bardenwerper, Visiting Professor; Professor Bardenwerper may be contacted at walter.bardenwerper@gmail.com].

Here are our objectives of the Kivalina case study in terms of what the learners or participants will be able to know or do as a result of the exercise. Learners will be able to:

- Recognize how trade-offs may need to be made to address sustainability risks and benefits;

- Improve their skills at analyzing and evaluating what processes might — or might not - be suitable tools for determining accountability and recovery for losses from industrial policies and choices;

- Articulate the challenges face by management and policy-makers in weighing costs and benefits, risks and rewards; and

- Evaluate the implications of how the decisions made in the ordinary course of a construction business might threaten individuals or groups unrelated to the building project or scope of a business.

Methods for the Kivalina Case Study. Professors Bardenwerper and Roe presented a brief overview of this case study at First All-Russia Conference on Interactive Teaching Methodology, held at Immanuel Kant Baltic Federal University (IKBFU) on 28-30 August 2018. Professor Bardenwerper also taught a version of this case study at the IKBFU Law School and School of Economics VII Summer School from 20-27 August 2018. The recommended sequence of activities of the class are as set out below, followed by brief teaching points:

1. Warm up: Ask participants, "When you hear the term "climate change," what do you think of?" This can be done individually or in pairs. Ask for volunteers, write responses on the board and briefly discuss. Teaching points: the purpose of this preliminary step is to engage the learners and to situate the concept in their experience. This primes the participants for learning in a number of ways: they link the concept to their own lives and prior knowledge, they collectively gather a variety of ideas connected with the concept, and, as they begin the activity with their own contributions, they gaining the experience of having a role in the development of the topic. In terms of cognitive psychology, they awaken their cognitive structures or schema and become ready to reinforce existing or build new connections among ideas. This step also helps the teacher to learn the extent to which the students might know or think about the subject.

For example, in a class for high school students on global warming, Professor Roe asked, "What do you think of when you hear the term, 'air pollution?" Here is the wide range of student responses: smoke, global warming, problem worsens over time, hard to stop, could have been stopped, other resources [are] implicated, regulations, factories, speaking up, good reasons, cars, causes of pollution are helpful, and jobs.

2. Read Kivalina facts (above). Teaching points: In addition to providing the participants with the basic facts, it's useful to have them process the facts to some degree in order to bring the concepts more fully into their experience. For example, the instructor can ask them to restate the facts in their own words, work in pairs to select the three most 
important facts or to construct a time line and/or to ask them what else they would like to know.

3. Watch Kivalina video https://youtu.be/SxzipQsf82c/. Teaching points: This short video graphically demonstrates the change in the quality of life of Kivalina and its inhabitants and captures the problem in economic and human terms from the villagers' perspective. The teacher should process the video in a manner similar to how they examined the facts. Such an approach should include what the video showed, and what it didn't show; what the students learned from it, and what in addition they would like to know. The teacher should consider adding a video that brings out the perspectives of the energy companies and/or larger economic data about relating to jobs and pollution, such as in the Washington Post article in FN 1.

4. Divide into two groups or more groups, depending on class size and objectives, with roles illustrating different viewpoints. For the purposes of this article we chose four different perspectives: oil executives, Kivalina villagers, environmental activists, and the industry group, Business Round Table. A moderator should be designated (either the teacher or participant). Teaching points: The number of roles can vary from two to four or more. Additional supplemental materials for each role group can also be provided, depending on the level of complexity the teacher intends to achieve. The moderator should be the teacher or a particularly able student capable of listening to the ideas presented and bringing out diverse views. The moderator should prepare questions for the various during the group preparation time.

5. Hand out the Role Sheet to each group:

Roles: You are a Kivalina villager, an oil company executive, an environmental activist or a Business Round Table member and have thought a lot about Sustainability Risk Management. You have been invited onto a major television show to address the role of the legal and legislative system (of Russia, the U.S. and/or international organizations) in determining responsibility for global climate change, assessing the financial accountability of the big energy companies to compensate the citizens of Kivalina and other communities that are facing possible harm as the climate warms or changes, and regulation of enterprises to reduce harm by climate change. During the show, you will have five minutes to make your presentation and, after all four representatives have spoken, three minutes to rebut the other sides. This will be followed by audience questions for the TV show participants. Teaching points: Engaging in a role requires the students to develop their role from two perspectives - from the interests of the character and the set of interests the role they are playing represents (the "internal" role) and the relationship of the character to the other characters (the "external" role). The teacher should encourage the students to be aware and attentive of these two dimensions of their roles.

6. Provide time for groups to discuss; groups develop arguments and designate spokespersons (e.g., 20 minutes). Teaching points: The goal of this group work is for students to learn from each other and advance their understanding of the roles and issues in a collaborative way. The quality of the students' collaborative, largely independent (from the teacher) group work is largely influenced not only by the quality of the problem but also by the earlier stages of the case study that open up the problem to the students' own experiences, perspectives and curiosity. The teacher should circulate and monitor the groups on their progress. The teacher should ask students to take notes or could also provide a more formally structured worksheet. The authors prefer less structured group work, as it provides the learners with greater autonomy and independence of thought.

7. Conduct a debate, hearing, community meeting or other interactive activity on proposed legislation or policy principles (here, we chose a TV show interview format with audience participation). Teaching points: This is the "presentation" aspect of the activity. The TV format chosen here is similar to but less formal than a debate. As the various 
participants explain their positions and respond to others, the issues should become clarified. The teacher should feel free to add questions or prompts during this segment if desired, perhaps by instituting a "freeze frame" or "commerical break" to steer or adjust the discussion. At the end of the presentations, the audience could be provided the opportunity to ask their own questions. This increases audience motivation to pay attention.

8. De-brief with the entire class regarding the merits of the positions presented, sources of perceptions, perspectives and biases, and other considerations. The teacher at this point should also ask students to remove themselves from their roles. The teacher should ask the class to briefly review what was positive or good about the presentations, and what they learned from it. For this, the teacher should adopt a positive, supportive and complimentary approach. The teacher could also ask the class to develop a list of policy recommendations as a result of what they learned. This can be done by the class as a whole or by shuffling the groups for additional small group work. The teacher should prepare for this segment of the lesson by reviewing the objectives (above) and evaluations (below) for the class to guide the debrief.

Evaluation of the Case Study: The evaluation is the third essential component of a lesson plan [FN - William Slattery, "Evaluation." Available at SERC Pedagogic Service, https://serc.carleton.edu/sp/library/assessment/index.html/] The plan should have at least one demonstrable component for each objective. While a full presentation of assessment is not possible in this paper, the authors intend to provide a detailed discussion of evaluations in a subsequent paper.

For this paper, we will examine the first objective, "Students will be able to recognize how trade-offs may need to be made to address sustainability risks and benefits." This objective is an introductory or preliminary one, as we are asking learners to recognize trade-offs at this point in the course trajectory, not to evaluate them. Our evaluation can be as simple as "to observe and describe compromises that students may propose or discuss in their group preparation, presentations, policy recommendations and concluding discussion." The teacher accomplishes this by circulating among the groups to observe and note the preparation and by observing and noting the points in the presentations where the parties appear to agree with and accept to some degree the differing interests of the other parties. In the final debrief, the teacher can specifically ask, "What trade-offs should the parties consider when fashioning policy proposals or climate agreements?" and write the student responses on the board. To record these comments, take a photo of the board before erasing it.

\section{Results and Discussion}

This paper demonstrates how a case study can be taught in an interactive way where the teacher serves as architect and coach of a series of activities. The activities shift the cognitive and expressive work of the class to the students, under the teacher's guidance. Through the various steps of the lesson, the participating students will engage in fact finding and assessment, synthesizing issues from the facts and narratives of the various roles and interests they represent, collaborating with their classmates in groups, fashioning solutions, considering diverse points of view, imaging what other factors they should consider, advocating for positions, and delving into the complexities of the problems of sustainability, among other high cognitive and expressive experiences.

In our example, we use a legal case not for purposes of legal analysis but rather as a focal point and point of departure for development of larger issues. The case is both concrete and generalizable, using an actual instance to approach more general, common and perhaps universal principles. In Kivalina, the courts find that there is no remedy for the harm the energy companies may have done to Kivalina and populations similarly situated 
everywhere. The fact that there is no existing legal remedy actually aids in the understanding of the problem of sustainability because there is no simple solution.

The core learning outcome of this lesson is that sustainability is a complex, multidimensional, and vast problem, and its resolution will require a complex, multidimensional, comprehensive, collaborative and integrated resolution process. The role of this particular lesson is to bring this to the surface. In the trajectory of a larger course on sustainability, learners will explore the nature of the problem at deeper levels and develop tools and principles to identify and resolve inharmonious and conflicting positions and interests through theoretical and practical aspects of risk management.

The authors believe that interactive learning provides high quality teaching and learning to help students master the concepts of sustainability risk management. We also put forth that interactive teaching and learning does more: through its methodology of experiential, learner centered engagement, it creates the experiences of collaborative, integrative, analytical, fact based and policy oriented reasoning that is necessary to comprehend and respond to a multidimensional problem.

\section{Conclusions}

The authors believe that interactive learning provides high quality teaching and learning to help students master the concepts of sustainability risk management. The use of cases and simulations drawn from actual events, or carefully developed by the instructor to illustrate the concepts that form the focus of the lesson, are highly effective vehicles for engaging learners in a manner, which transcends simple exposition via lecture or other forms of teacher-dominated presentation. We put forth that interactive teaching and learning does more: through its methodology of experiential, learner centered engagement, it creates the experiences of collaborative, integrative, analytical, fact based and policy oriented reasoning that is necessary to comprehend and respond to a multidimensional problem.

\section{References}

1. Victoria Borkovskaya, Walter Bardenwerper, Richard Roe. Interactive Teaching of Risk Management in the Russian Construction Industry. IOP Conf. Series: Materials Science and Engineering 365 (2018) 062030. DOI:10.1088/1757-899X/365/6/062030.

2. Borkovskaya V.G, Bardenwerper W, Roe R. Sustainability Risk Management: The Case for Using Interactive Methodologies for Teaching, Training and Practice in Environmental Engineering and Other Fields. Advances in Economics, Business and Management Research (France-Netherlands). Atlantis Press. In press.

3. Clean Up Climate Change? It's Just Good for Business," Washington Post, October 12, 2018, at www.washingtonpost.com/business/economy/clean-up-climate-change-itsjust-good-for-business/2018/10/12/30f13e40-cda2-11e8-

920fdd52e1ae4570_story.html?utm_term $=.65 \mathrm{ac}-59 \mathrm{a} 0 \mathrm{c} 406$

4. World Commission on Environment and Development (1987). Our Common Future. Oxford: Oxford University Press

5. PRESS RELEASE "Baltimore Takes on Fossil Fuel Companies To Protect Taxpayers from the Costs and Consequences of Climate Change," Office of the Mayor, City of Baltimore, Maryland, July 20, 2018; "Three Californian Communities Sue 37 "Carbon Majors" Seeking Compensation for Costs of Adapting to Sea Level Rises Linked to Climate Change," Business and Human Rights Resource Centre, March 22, 2018 (Internet); Daniel A. Farber, "Basic Compensation For Victims of Climate Change," 155 U. Penn L. Rev. 1605 (2007 
6. Kivalina, Alaska: Eroding Village Appeals Lawsuit's Dismissal, Blames Corporations For Climate Change". Huffington Post. 2010-01-28

7. Montague, Ada C. (2013) "Native Village of Kivalina v. ExxonMobil Corp.," Public Land and Resources Law Review: Vol. 0 , Article 15. Available at: https://scholarship.law.umt.edu/plrlr/vol0/iss3/15

8. Native Village of Kivalina v. ExxonMobil Corp., 696 F.3d 849, 2012 (9th Cir. 2012

9. Michelle Schwartz, Instructional Design and Research Strategist, "Teaching Methods for Case Studies, the Learning \& Teaching Office, Ryerson College, 2014, available at http://ryerson.ca/lt

10. Ann Velenchik, "Teaching with the Case Method, SERC Pedagogic Service Project, Carlton College. Available at https://serc.carleton.edu/econ/cases/index.html

11. See Syllabus: "Enterprise Risk Management, Fourth Quarter 2017, Peking University School of Transnational Law," Professor Walter Bardenwerper, Visiting Professor; Professor Bardenwerper may be contacted at walter.bardenwerper@gmail.com

12. William Slattery, "Evaluation." Available at SERC Pedagogic Service, https://serc.carleton.edu/sp/library/assessment/index.htm 